\title{
Active commuting to and from university, obesity and metabolic syndrome among Colombian university students
}

\author{
Antonio García-Hermoso ${ }^{1}$, Andrea P. Quintero², Enrique Hernández², Jorge Enrique Correa-Bautista², \\ Mikel Izquierdo ${ }^{3}$, Alejandra Tordecilla-Sanders², Daniel Prieto-Benavides², Carolina Sandoval-Cuellar ${ }^{2,4}$, \\ Katherine González-Ruíz ${ }^{5}$,Emilio Villa-González ${ }^{6}$ and Robinson Ramírez-Vélez ${ }^{2 *}$
}

\begin{abstract}
Background: There is limited evidence concerning how active commuting (AC) is associated with health benefits in young. The aim of the study was to analyze the relationship between AC to and from campus (walking) and obesity and metabolic syndrome (MetS) in a sample of Colombian university students.

Methods: A total of 784 university students ( $78.6 \%$ women, mean age $=20.1 \pm 2.6$ years old) participated in the study. The exposure variable was categorized into AC (active walker to campus) and non-AC (non/infrequent active walker to campus: car, motorcycle, or bus) to and from the university on a typical day. MetS was defined in accordance with the updated harmonized criteria of the International Diabetes Federation criteria.

Results: The overall prevalence of MetS was 8.7\%, and it was higher in non-AC than AC to campus. The percentage of AC was $65.3 \%$. The commuting distances in this AC from/to university were $83.1 \%, 13.4 \%$ and $3.5 \%$ for $<2 \mathrm{~km}, 2$ $5 \mathrm{~km}$ and $>5 \mathrm{~km}$, respectively. Multiple logistic regressions for predicting unhealthy profile showed that male walking commuters had a lower probability of having obesity [OR $=0.45$ (Cl 95\% 0.25-0.93)], high blood pressure $[O R=0.26(\mathrm{Cl} 95 \% 0.13-0.55)]$ and low HDL cholesterol $[\mathrm{OR}=0.29(\mathrm{Cl} 95 \% 0.14-0.59)]$ than did passive commuters.
\end{abstract}

Conclusions: Our results suggest that in young adulthood, a key life-stage for the development of obesity and MetS, AC could be associated with and increasing of daily physical activity levels, thereby promoting better cardiometabolic health.

Keywords: Active transport, Physical activity, Cardiometabolic risk, Young adults

\section{Background}

Metabolic syndrome (MetS) is a complex clustering of cardiovascular risk factors, such as abdominal obesity, hypertension, diabetes and dylipedemia [1], and consists of several cardiovascular risk factors that coexist and promote cardiovascular morbidity and mortality [2]. Accumulating data point towards the beneficial role of physical activity (PA) on promoting the control of individual cardiovascular risk factors, such as obesity,

\footnotetext{
* Correspondence: robin640@hotmail.com; robinson.ramirez@urosario.edu.co ${ }^{2}$ Centro de Estudios para la Medición de la Actividad Física «CEMA». Escuela de Medicina y Ciencias de la Salud, Universidad del Rosario, Bogotá D.C, Colombia

Full list of author information is available at the end of the article
}

diabetes mellitus, and hypertension [3]. However, physical inactivity is a growing contributing cause to at least 35 unhealthy conditions, including the MetS, worldwide [4]. For example, in Colombia, it is estimated that only $51.3 \%$ of men and women aged 18-64 years achieve recommended daily levels of physical activity [5]. In this sense, one of the key changes in young adult life occurs during the transition from high school to university, and a decrease in PA levels is associated with this period [6]. University life appears to keep students physically inactive for long periods, which results in a reduction of the overall PA practice without meeting the recommended PA levels [7].

(c) The Author(s). 2018 Open Access This article is distributed under the terms of the Creative Commons Attribution 4.0 International License (http://creativecommons.org/licenses/by/4.0/), which permits unrestricted use, distribution, and 
One important factor that contributes to low PA levels is an increase in the use of passive modes of transportation [8]. Walking and cycling to university may offer young people an opportunity to incorporate physical activity into their daily lives. Active commuting (AC) as a daily behavior is considered an opportunity to create a healthy habit, increasing PA levels and reducing the risk of cardiovascular disease, an improved metabolic profile and many other noted health benefits in youth $[9,10]$ and adult populations [11]. However, limited studies have analyzed AC in the collegiate student population and its positive benefits [12-14]. In two successive studies, Bopp et al. [12, 13] suggested that active travelers had greater cardiovascular fitness, were more flexible, and had lower systolic blood pressure and probability to be overweight compared with non-active travelers. In addition, Gordon-Larsen et al. [14] suggested that AC was positively associated with fitness in young adult men and women (18-30 years old) and was inversely associated with body mass index (BMI), central obesity, triglyceride levels, blood pressure, and insulin levels in males.

$\mathrm{AC}$ is an important strategy to promote PA in keeping with recommendations proposed by international bodies and the high rates of physical inactivity and sedentary lifestyles among students in Bogotá (Colombia). However, to the best of our knowledge, this study is the first to analyze the AC behavior of Latino university students. Thus, our study analyzed the relationship between AC to and from university (walking) and obesity and MetS in a sample of Colombian university students.

\section{Methods}

\section{Study design and sample population}

During the 2014-2017 academic years, we reviewed a cross-sectional component of the FUPRECOL (in Spanish Asociación de la Fuerza Prensil con Manifestaciones Tempranas de Riesgo Cardiovascular en Adultos Colombianos) Adults study, which investigated the association between muscular strength and cardiometabolic risk factors in a sample of Colombian university students. We recently published a complete description of the FUPRECOL Adults study design, methods, and primary outcomes for our current cohort [15]. The original sample consisted of adults (men: $n=706$; women: $n=1126$ ). From this subgroup, 784 university students ( $78.6 \%$ women) had valid data in $\mathrm{AC}$ and all components included in the cardiometabolic variables and $\mathrm{AC}$ survey. There were no differences in the study key characteristics (i.e., age, sex distribution, BMI, and MetS components) between the current study sample and the original FUPRECOL Adults Study sample $(n=1832$, all $p>0.100$ ). Data were collected in Tunja, a city in the Eastern Range of the Colombian Andes in a region known as the Altiplano Cundiboyacense, located $130 \mathrm{~km}$ northeast of Bogotá. In 2016, this city had an estimated population of 191,878 inhabitants. The city center is at an elevation of $2820 \mathrm{~m}(9,250 \mathrm{ft})$ above sea level. Tunja is an important educational center and is home to several well-known universities.

\section{Measurements \\ Anthropometry and body fatness}

Subjects were tested while wearing light clothing (shoes were removed). Height (Seca ${ }^{\circ}$ 274, Hamburg, Germany), body mass (Model Tanita ${ }^{\circ}$ BC-420 ${ }^{\circ}$, Tokyo, Japan) and waist circumference (WC, Lufkin W606 $\mathrm{PM}^{\circ}$, Parsippany, NJ, USA) were assessed according to international standards for anthropometric assessment [16]. The height and body mass measurements were used to calculate the BMI $=$ body mass $(\mathrm{kg}) /$ height $\left.(\mathrm{m})^{2}\right]$. Trained researchers performed the measurements according to standardized procedures. The technical error of measurement values was less than $2 \%$ for all anthropometric variables. $\mathrm{BF} \%$ was determined by a tetrapolar whole body impedance (Tanita Model BC-420, Tokyo, Japan). A detailed description of the bioelectrical impedance analysis technique was presented in a previous study [17]. The corresponding intra-observer technical error (\% reliability) of the measurements was $95 \%$.

\section{Cardiometabolic variables}

Blood pressure was obtained using an automatic monitor (Omrom ${ }^{\circ}$ HEM 705 CP, Health-care Co, Kyoto, Japan) following a previously described protocol for the European Heart Society (on the right arm with participants in a supine position and subjects rested quietly for $10 \mathrm{~min}$ in a comfortable chair). The mean arterial blood pressure (MAP) was calculated as: $(2 \mathrm{x}$ diastolic) +systolic]/3 [18].

Blood samples $(40 \mu \mathrm{L})$ were drawn between 07:00 and 09:00, after 10-12 $\mathrm{h}$ of fasting (11.2 $\mathrm{h}$ on average). Hematological entities, including total cholesterol (TC), high-density lipoprotein cholesterol (HDL-C), and triglycerides (TG), were measured by using an automated biochemical analyzer Cardiocheck ${ }^{\circ}$ equipment (Mexglobal SA, Parsippany, NJ, USA). Low-density lipoprotein-cholesterol (LDL-C) was calculated using Friedewald's Formula when triglyceride values were $\leq 400 \mathrm{mg} / \mathrm{dL}$ [19]. Glucose was measured using Accu-Chek ${ }^{\bullet}$ Aviva Plus system (Roche ${ }^{\circ}$, Mexglobal SA, Terrytown, NY, USA).

MetS was defined in accordance with the updated harmonized criteria of the International Diabetes Federation/ National Heart, Lung and Blood Institute/American Heart Association (IDF/NHLBI/AHA-2009) [20]. Participants were considered to have MetS if they showed three or more of the following: (1) central obesity in WC $(q \geq 80 \mathrm{~cm}$ and $\hat{\delta} \geq 90 \mathrm{~cm})$; (2) TG $(\geq 150 \mathrm{~g} / \mathrm{dL})$; (3) 
low HDL-C ( $q<50 \mathrm{mg} / \mathrm{dL}$ and $\hat{\sigma}<40 \mathrm{mg} / \mathrm{dL}$ ); (4) high blood pressure (systolic blood pressure $\geq 130 \mathrm{mmHg}$ or diastolic blood pressure $\geq 85 \mathrm{mmHg}$ ); (5) high TG $(\geq 100 \mathrm{mg} / \mathrm{dL}$ ). The latest (IDF/NHLBI/AHA-2009) consensus stated that WC was measured according to Country/Specific values which, for Latin Americans, were set to be equal to South Asian parameters, specifically $\mathrm{WC} \geq 90 \mathrm{~cm}$ for males and $\geq 80 \mathrm{~cm}$ for women [20].

\section{Modes of commuting to/from the university}

The mode of commuting to and from school was measured using a questionnaire developed and validated in Spanish by the University of Granada (Spain) through the project "PACO: pedalea y anda al colegio" (http:// profith.ugr.es/paco). This questionnaire has been validated in a Spanish population [21, 22]. The usual mode of commuting to and from campus was categorized into "active" commuting (active walker to campus) and nonactive commuting (non/infrequent active walker to campus: car, motorcycle, or bus). Although this particular question for assessing commuting to/from university has not been formally validated, it is highly similar to other 1-item questionnaires on a students' commuting to university that have been demonstrated to be acceptably reliable and valid in this age group [23]. For commuting distance from home to their university participants could choose any of the following options: 0 to $2 \mathrm{~km}, 2$ to $5 \mathrm{~km}$, and $>5 \mathrm{~km}$. In our sample, the results of analysis internal consistency reveal that Colombian version of the project "PACO: pedalea y anda al colegio" scale have adequate to good values (commuting to/from university and barriers domain $\alpha$ Cronbach $=0.761$, and total commuting distance from home to their university or vice versa domain $\alpha$ Cronbach $=0.995$ ). Finally, due to a limited number of students who cycle to the university $(n=9)$, we have removed these individuals from the study population.

\section{Lifestyle covariates}

A validated questionnaire, the "FANTASTIC" lifestyle, was used to collect comprehensive information about substance use via a personal interview with participants. Alcohol consumption (No or 1 to 10 cigarettes per day), smoking status (No or 1 to 9 times per week), and physical activity levels ( 5 times a week for $>30 \mathrm{~min}$ or $\geq 150$ min per week were categorized as "physically active") has been previously described by RamírezVélez et al. [24].

The seven-day recall dietary assessment tool was used to complete the MetDiet. As suggested by Thanapoulou et al. [25], the total score was divided into two categories of Mediterranean diet quality: $\leq 8$ points = poor diet quality and $\geq 9$ points = good diet quality (optimal Mediterranean diet style). Participants who had $\geq 9$ points were categorized as having an ideal healthy diet, whereas those with 8 points or less were classified as having a non-ideal diet. Personal, family history of CVD, and medication use was used as covariables.

\section{Ethics statement}

The study was approved by the Research Ethics Committee at the Universidad Manuela Beltrán (UMB Code $\mathrm{N}^{\circ}$ 01-1802-2013) in according the Helsinki Declaration Accord (World Medical Association for Human Subjects, 2000). Informed consent was obtained from each participant before being enrolled in the study.

\section{Statistical analysis}

Anthropometric and body composition components and cardiometabolic risk factors of the study sample are presented as the mean (SD) or relative frequency, $\mathrm{n}(\%)$. The normality of the variables was verified using histograms and Q-Q plots. Differences on cardiometabolic parameters between walking and non-walking groups were assessed using an ANOVA or $\mathrm{X}^{2}$ test. Finally, to examine the OR and 95\% CI of having an unhealthy profile (MetS components), we used multinomial logistic regression by sex. The exposure variable was categorized into AC (active walker to campus) and non-AC (non/infrequent active walker to campus: car, motorcycle, or bus) to and from the university on a typical day. These analyses were adjusted by age, BMI (only when obesity or waist circumference were not included as dependent variable), PA, alcohol and tobacco intake, diet, and distance and were performed using SPSS version 21.0 for Windows (IBM, Armonk, New York). Statistical significance was established at $p<0.05$.

\section{Results}

The sample consisted of 784 university students from Tunjá, Boyacá. Characteristics of the whole sample were categorized in passive and active commuters are shown in Table 1. In the present study, the percentage of active commuters (i.e., walkers to/from the university) was 65 . $3 \%$. The commuting distances in this active commuters from/to university were $83.1 \%, 13.4 \%$ and $3.5 \%$ for $<2 \mathrm{~km}$, $2-5 \mathrm{~km}$ and $>5 \mathrm{~km}$, respectively.

There were no significant differences for the majority of the study variables between active and passive commuters to and from the university. Regarding lifestyle, a greater percentage of PA levels ( $\geq 150$ min per week) were shown in passive compared to active commuters $(28.3 \%$ vs. $19.7 \%$ respectively; $p=0.006)$. The passive commuters showed a higher height $(p<0.001)$ but lower $\%$ and $\mathrm{kg}$ of fat mass ( $p<0.001$ and $p=0.010$, respectively) than active commuters. With respect to cardiometabolic risk factors, there were only significant differences in waist circumference $(p=0.004)$ and triglycerides $(p=0.003)$ 
Table 1 Characteristics of the sample

\begin{tabular}{|c|c|c|c|c|}
\hline & Total $(n=784)$ & $\begin{array}{l}\text { Non/infrequent active walker } \\
\text { to campus }(n=272)\end{array}$ & $\begin{array}{l}\text { Active walker to } \\
\text { campus }(n=512)\end{array}$ & $p$ \\
\hline \multicolumn{5}{|l|}{ Sex } \\
\hline Male, n (\%) & $168(21.4)$ & $95(34.9)$ & $73(14.3)$ & \\
\hline Female, n (\%) & $616(78.6)$ & $177(65.1)$ & $439(85.7)$ & \\
\hline Age & $20.0(2.6)$ & $20.1(2.7)$ & $20.0(2.6)$ & 0.558 \\
\hline \multicolumn{5}{|l|}{ Life-style } \\
\hline Tobacco (1 to 10 cigarettes per day), n (\%) & $213(28.7)$ & $74(27.2)$ & $139(28.8)$ & 0.939 \\
\hline Alcohol (1 to 9 times per week), n (\%) & $371(47.8)$ & $128(47.1)$ & $243(47.9)$ & 0.927 \\
\hline PA levels ( $\geq 150$ min per week), $n(\%)^{a}$ & $177(22.7)$ & $77(28.3)$ & $100(19.7)$ & 0.006 \\
\hline MetDiet ( $\geq 9$ points), n (\%) & $247(31.5)$ & $73(27.0)$ & $184(36.0)$ & 0.430 \\
\hline \multicolumn{5}{|l|}{ Anthropometric and body composition } \\
\hline Weight & $60.7(11.7)$ & $61.8(12.5)$ & $60.2(11.3)$ & 0.058 \\
\hline Height & $161.4(8.0)$ & $163.4(8.6)$ & $160.3(7.5)$ & $<0.001$ \\
\hline Body mass index & $23.2(3.8)$ & $23.1(4.0)$ & $23.3(3.6)$ & 0.398 \\
\hline Obese, n (\%) ${ }^{a}$ & $212(27.0)$ & $70(25.7)$ & $142(27.7)$ & 0.547 \\
\hline Fat mass, $\%$ & $24.9(8.4)$ & $22.9(9.1)$ & $26.0(7.7)$ & $<0.001$ \\
\hline Fat mass, kg & $15.6(7.5)$ & $14.6(8.2)$ & $16.1(7.2)$ & 0.010 \\
\hline \multicolumn{5}{|l|}{ Cardiometabolic risk factors } \\
\hline Waist circumference, cm & $72.4(8.0)$ & $73.6(9.5)$ & $71.7(8.0)$ & 0.004 \\
\hline Increased waist circumference, $\mathrm{n}(\%)^{\mathrm{a}}$ & $104(13.4)$ & $37(13.8)$ & $67(13.2)$ & 0.818 \\
\hline Triglycerides, mg/dL & $89.3(44.7)$ & $95.9(50.0)$ & $85.7(41.3)$ & 0.003 \\
\hline High triglycerides, $n(\%)^{a}$ & $68(8.7)$ & $29(10.8)$ & $39(7.7)$ & 0.143 \\
\hline HDL cholesterol, mg/dL & $40.6(11.5)$ & $41.4(11.3)$ & $40.1(11.6)$ & 0.132 \\
\hline Low HDL cholesterol, n (\%) ${ }^{a}$ & $582(74.9)$ & $188(69.1)$ & $342(66.9)$ & 0.601 \\
\hline Fasting plasma glucose, mg/dL & $87.7(9.2)$ & $87.8(9.7)$ & $87.6(8.9)$ & 0.780 \\
\hline High fasting plasma glucose & $77(9.8)$ & $28(10.4)$ & $49(9.6)$ & 0.728 \\
\hline Mean blood pressure, $\mathrm{mmHg}$ & $92.9(9.1)$ & $92.3(8.8)$ & $93.2(9.2)$ & 0.204 \\
\hline High blood pressure & $165(21.2)$ & $60(22.0)$ & $100(19.6)$ & 0.418 \\
\hline Metabolic syndrome, n (\%) ${ }^{\mathrm{a}}$ & $67(8.7)$ & $24(9.1)$ & $43(8.5)$ & 0.813 \\
\hline
\end{tabular}

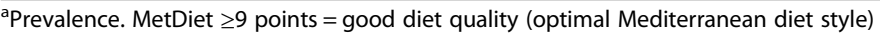

with higher values in the passive commuters. The overall prevalence of MetS was $8.7 \%$, and it was higher in non$\mathrm{AC}$ than AC to campus.

The multiple logistic regressions for predicting an unhealthy profile showed that male walking commuters had a lower probability of having obesity [OR $=0.45(\mathrm{CI}$ 95\% 0.25-0.93); $p=0.031$, high blood pressure [OR $=0$. 26 (CI 95\% 0.13-0.55); $p<0.001]$ and low HDL cholesterol $[\mathrm{OR}=0.29$ (CI 95\% 0.14-0.59); $p=0.001]$ than did passive commuters (Fig. 1).

\section{Discussion}

This study analyzes the relationship between $\mathrm{AC}$ to/from the university (walking), body composition, MetS and its components in a sample of Colombian university students.
The percentage of active commuters (i.e., walkers to/from the university) was 65.3\%; paradoxically, there were a greater percentage of PA levels ( $\geq 150$ min per week) in passive compared to active commuters $(28.3 \%$ vs $19.7 \%$, respectively). Overall, male active commuters had a lower probability of having obesity, high blood pressure and low HDL cholesterol than did active commuters. Therefore, university students could benefit from participation in this behavior by increasing their knowledge regarding the importance and benefits of these sustainable modes of transportation [11]. However, the positive metabolic effects of active commuting reported based on the logistic regressions apply exclusively to male participants, which make only $21.4 \%$ of the study sample and therefore caution is warranted when interpreting data. 

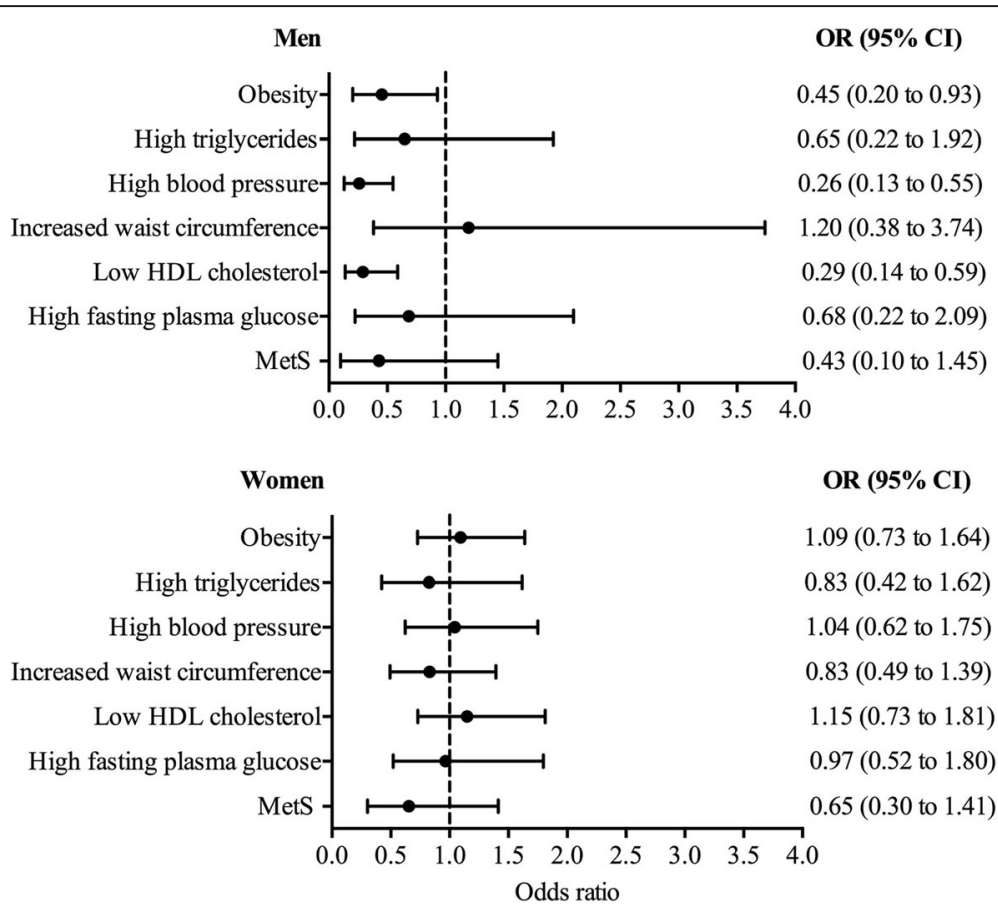

Fig. 1 Multiple logistic regressions predicting unhealthy profile according to active walking to university categories (active or passive) using bivariate analysis by sex. Reference: Passive commuters (OR, 1.0). Analysis adjusted for age, body mass index (except for waist circumference included as dependent variable), physical activity, alcohol and tobacco intake, diet, and distance

During transition from adolescence to young adulthood, the risk of physical inactivity and obesity becomes more prevalent; thus, it is essential to have a better understanding of the students' behaviors to develop strategies to prevent certain of these negative health outcomes. With respect to prevalence of obesity, our results are consistent with previous studies, which have determined that daily walking to different places (e.g., to/from school or work) is not sufficient stimulus to generate changes in the body composition in women, although it does generate changes in males $[14,26]$. In a young adult population, Gordon-Larsen et al. [14] suggested that the reason for the lack of associations for women could be that they may have a lower intensity of activity during AC. Since there were few university students who cycle to the university, we cannot confirm this hypothesis about AC intensity. In contrast, other studies have shown a relationship between $\mathrm{AC}$ and obesity in both sexes [27, 28]. Therefore, walking behavior can be integrated into other activities beyond leisure into AC and overall lifestyle activity, which could reduce obesity prevalence.

A recent meta-analysis from 16 prospective studies suggests a negative linear association between leisuretime physical activity and the incident MetS across the identified cohorts with a reduction of MetS risk by $8 \%$ per $10 \mathrm{MET}$ h/week increments in leisure-time physical activity. With double the minimum recommended levels, the risk was reduced $20 \%$ [29]. In this respect, walking commuting has been recommended as a feasible method of incorporating greater levels of PA into daily life [30]. A previous meta-analysis reported that $\mathrm{AC}$ (no differentiation between commuting by walking and cycling) is related to a lower risk of adverse cardiovascular outcomes [30]. Another research study from the UK BIOBANK study consisting of 263,540 adults suggested that walking commuting is associated with a lower risk of cardiovascular disease incidence and mortality in a dosedependent manner and independent of a range of confounding factors [11]. Regarding the Latino population, a recent study published by Steell et al. [31], based on data from participants aged $\geq 15$ years from the 2009-10 Chilean National Health Survey, showed an association between AC and lower adiposity and odds for cardiovascular risk factors (diabetes and MetS) but did not identify any association between active commuting and HDL-cholesterol or blood pressure. In this sense, the results of these studies showed inconsistent conclusions about AC and metabolic health. Our study suggested that active commuters had a lower probability of having high blood pressure and low HDL cholesterol compared to walking commuters. Confirming our findings, the CARDIA Study reported that AC was inversely related with triglyceride levels, blood pressure, and insulin level in males [14]. In addition, two studies in a Chinese adult population published by $\mathrm{Hu}$ et al. [26, 32] observed no 
association between $\mathrm{AC}$ and diastolic blood pressure or HDL-cholesterol in males, but the association was significant for women. As previously described, the lack of information regarding the intensity of PA could explain the discrepancies observed between studies.

\section{Limitations}

Due to the cross-sectional nature of the study design, we were unable to draw causal relationships. In addition, we analyzed relatively healthy university students; thus, the generalization of our results is limited to this population. The use of a self-reported method introduces further limitations, including the possibility of bias and unknown validity or reliability. Also, FUPRECOL Adults Study participants were asked to provide their main commuting mode; thus, mixed-mode journeys were not captured. It is therefore likely that the students who reported using a form of public transport as their main mode of transportation were highly heterogeneous in terms of the levels of PA that their commutes entailed. Finally, other pertinent factors such as sedentary behaviour and sleep were not considered.

\section{Conclusions}

$\mathrm{AC}$ to and from the university could be an useful strategy to improve health in university students, since male walking commuters showed a lower probability of having obesity, low HDL-C and high blood pressure than did passive commuters. Taken together, these findings suggest that in young adulthood, a key life-stage for the development of obesity and MetS, AC could be a useful means of increasing daily PA levels, thereby promoting better cardiometabolic health. However, further research is warranted to understand the relationship between AC and cardiovascular risk factors in university students.

\section{Abbreviations \\ AC: Active commuting; BMI: Body mass index; HDL-C: High-density lipoprotein-cholesterol; LDL-C: Low-density lipoprotein-cholesterol; MetS: Metabolic syndrome; PA: Physical activity; TC: Total cholesterol; TG: Triglycerides; WC: Waist circumference}

\section{Acknowledgements}

The authors gratefully acknowledge the contributions of Elisa Andrea Cobo, Boyacá University who assisted the authors with obtaining data. We also acknowledge Monica Ojeda, Boyacá University, for assistance with data analysis. Both of their contributions were without compensation.

\section{Funding}

This study was part of the project entitled "Body Adiposity Index and Biomarkers of Endothelial and Cardiovascular Health in Adults", which was funded by Centre for Studies on Measurement of Physical Activity, School of Medicine and Health Sciences, Universidad del Rosario (Code N FIUR DNBG001) and Universidad de Boyacá (Code N RECT 60). The funder had no role in the study design, data collection, data analysis and interpretation, preparation of the manuscript, or decision to publish.

Availability of data and materials

The data used in this study are available under request.

\section{Authors' contributions}

AG-H, APQ and RR-V conceived and designed the project. KG-R, CS-C, EH, AT-S and JEC-B reviewed the literature studies and conducted data extraction. AG-H and RR- $\mathrm{V}$ conducted data analyses. RR-V, MI, AG-H and DP-B were responsible for data interpretation. MI, AG-H and RR-V drafted the manuscript, and EV-G, and $\mathrm{EH}$ revised it critically for intellectual contributions. KG-R, CS-C and RR-V coordinate the study development. All authors reviewed and edited the manuscript. All authors read and approved the final manuscript.

\section{Ethics approval and consent to participate}

Written informed consent was obtained from all participants. This study was conducted according to the guidelines laid down in the Declaration of Helsinki (2000) and was approved by the regional Ethics Committee for Medical Research Ethics Committee of The Universidad Manuela Beltrán (UMB Code N 01-1802-2013).

\section{Competing interests}

The authors declare that they have no competing interests.

\section{Publisher's Note}

Springer Nature remains neutral with regard to jurisdictional claims in published maps and institutional affiliations.

\section{Author details}

${ }^{1}$ Laboratorio de Ciencias de la Actividad Física, el Deporte y la Salud, Facultad de Ciencias Médicas, Universidad de Santiago de Chile, USACH, Santiago, Chile. ${ }^{2}$ Centro de Estudios para la Medición de la Actividad Física «CEMA». Escuela de Medicina y Ciencias de la Salud, Universidad del Rosario, Bogotá D.C, Colombia. ${ }^{3}$ Department of Health Sciences, Public University of Navarre, CIBERFES (CB16/10/00315), Navarre, Spain. ${ }^{4}$ Programa de Fisioterapia, Facultad de Ciencias de la Salud, Universidad de Boyacá, Facultad de Ciencias de la Salud, Boyacá 150003, Colombia. ${ }^{5}$ Grupo de Ejercicio Físico y Deportes, Vicerrectoría de Investigaciones, Universidad Manuela Beltrán, Bogotá D.C, Colombia. ${ }^{6}$ PROFITH "PROmoting FITness and Health through Physical Activity“ Research Group, Department of Physical Education and Sport, School of Sport Sciences, University of Granada, Granada, Spain.

Received: 27 December 2017 Accepted: 12 April 2018

Published online: 19 April 2018

\section{References}

1. Zimmet P, Magliano D, Matsuzawa Y, Alberti G, Shaw J. The metabolic syndrome: a global public health problem and a new definition. J Atheroscler Thromb. 2005;12(6):295-300.

2. Spalding A, Kernan J, Lockette W. The metabolic syndrome: a modern plague spread by modern technology. J Clin Hypertens. 2009;11(12):755-60.

3. Haskell WL, Lee I-M, Pate RR, Powell KE, Blair SN, Franklin BA, et al. Physical activity and public health: updated recommendation for adults from the American College of Sports Medicine and the American Heart Association. Circulation. 2007;116(9):1081.

4. Booth FW, Roberts CK, Thyfault JP, Ruegsegger GN, Toedebusch RG. Role of inactivity in chronic diseases. Evolutionary insight and pathophysiological mechanisms. Physiol Rev. 2017;97(4):1351-402.

5. Encuesta Nacional de Situación Nutricional. Encuesta Nacional de la Situación Nutricional en Colombia ENSIN-2015; https://www.minsalud.gov. co/salud/publica/epidemiologia/Paginas/encuesta-nacional-de-situacionnutricional-ensin.aspx. Accessed 15 Mar 2018.

6. Molina-García J, Queralt A, Castillo I, Sallis JF. Changes in physical activity domains during the transition out of high school: psychosocial and environmental correlates. J Phys Act Health. 2015;12(10):1414-20.

7. Clemente FM, Nikolaidis PT, Martins FML, Mendes RS. Physical activity patterns in university students: Do they follow the public health guidelines? PLoS One. 2016;11(3):e0152516.

8. Flint E, Cummins S, Sacker A. Associations between active commuting, body fat, and body mass index: population based, cross sectional study in the United Kingdom. BMJ. 2014;349:94887.

9. Gutiérrez-Zornoza M, Sánchez-López M, García-Hermoso A, González-García A, Chillón P, Martínez-Vizcaíno V. Active commuting to school, weight status, and cardiometabolic risk in children from rural areas: the Cuenca study. Health Educ Behav. 2015;42(2):231-9. 
10. Ramírez-Vélez R, García-Hermoso A, Agostinis-Sobrinho C, Mota J, Santos R Correa-Bautista JE, et al. Cycling to school and body composition, physical fitness, and metabolic syndrome in children and adolescents. J Pediatr. 2017:188:57-63.

11. Celis-Morales CA, Lyall DM, Welsh P, Anderson J, Steell L, Guo Y, et al. Association between active commuting and incident cardiovascular disease, cancer, and mortality: prospective cohort study. BMJ. 2017;357: j1456.

12. Bopp M, Behrens TK, Velecina R. Associations of weight status, social factors, and active travel among college students. Am J Health Educ. 2014;45(6): 358-67.

13. Bopp M, Bopp C, Schuchert M. Active transportation to and on campus is associated with objectively measured fitness outcomes among college students. J Phys Act Health. 2015;12(3):418-23.

14. Gordon-Larsen P, Boone-Heinonen J, Sidney S, Sternfeld B, Jacobs DR, Lewis CE. Active commuting and cardiovascular disease risk: the CARDIA study. Arch Intern Med. 2009:169(13):1216-23.

15. Ramírez-Vélez R, Correa-Bautista JE, Sanders-Tordecilla A, Ojeda-Pardo ML, Cobo-Mejía EA, Castellanos-Vega RP, et al. Percentage of body fat and fat mass index as a screening tool for metabolic syndrome prediction in Colombian university students. Nutrients. 2017;9(9):1009.

16. Marfell-Jones MJ, Stewart A, De Ridder J: International standards for anthropometric assessment; 2012

17. Rodríguez-Rodríguez F, Cristi-Montero C, González-Ruíz K, Correa-Bautista JE, Ramírez-Vélez R. Bioelectrical impedance vector analysis and muscular fitness in healthy men. Nutrients. 2016;8(7):407.

18. Mancia G, Fagard R, Narkiewicz K, Redán J, Zanchetti A, Böhm M, et al. 2013 practice guidelines for the management of arterial hypertension of the European Society of Hypertension (ESH) and the European Society of Cardiology (ESC): ESH/ESC task force for the Management of Arterial Hypertension. J Hypertens. 2013;31(10):1925-38.

19. Friedewald WT, Levy RI, Fredrickson DS. Estimation of the concentration of low-density lipoprotein cholesterol in plasma, without use of the preparative ultracentrifuge. Clin Chem. 1972;18(6):499-502.

20. Alberti K, Eckel R, Grundy S, Zimmet P, Cleeman J, Donato K. Harmonizing the metabolic syndrome. A joint interim statement of the IDF task force on epidemiology and prevention; NHL and Blood Institute; AHA; WHF; IAS; and IA for the study of obesity. Circulation. 2009;120(16):1640-5.

21. Chillón P, Herrador-Colmenero M, Migueles JH, Cabanas-Sánchez V, Fernández-Santos JR, Veiga ÓL, et al. Convergent validation of a questionnaire to assess the mode and frequency of commuting to and from school. Scand J Public Health. 2017;45(6):612-20.

22. Herrador-Colmenero M, Pérez-García M, Ruiz JR, Chillón P. Assessing modes and frequency of commuting to school in youngsters: a systematic review. Pediatr Exerc Sci. 2014;26(3):291-341.

23. Molina-García J, Sallis JF, Castillo I. Active commuting and sociodemographic factors among university students in Spain. J Phys Act Health. 2014;11(2):359-63.

24. Ramírez-Vélez R, Agredo RA. The Fantastic instrument's validity and reliability for measuring Colombian adults' life-style. Rev Salud Publica. 2012; 14(2):226-37.

25. Thanopoulou A, Karamanos B, Angelico F, Assaad-Khalil S, Djordjevic P, Katsilambros $\mathrm{N}$, et al. Epidemiological evidence for the non-random clustering of the components of the metabolic syndrome: multicentre study of the Mediterranean Group for the study of diabetes. Eur J Clin Nutr. 2006; 60(12):1376-83.

26. Hu G, Pekkarinen H, HÄnninen O, Yu Z, Guo Z, Tian H. Commuting, leisuretime physical activity, and cardiovascular risk factors in China. Med Sci Sports Exerc. 2002;34(2):234-8.

27. Lindström M. Means of transportation to work and overweight and obesity: a population-based study in southern Sweden. Prev Med. 2008; 46(1):22-8.

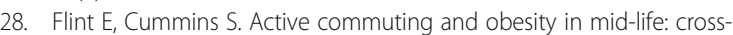
sectional, observational evidence from UK Biobank. Lancet Diabetes Endocrinol. 2016:4(5):420-35.

29. Zhang D, Liu X, Liu Y, Sun X, Wang B, Ren $Y$, et al. Leisure-time physical activity and incident metabolic syndrome: a systematic review and dose-response meta-analysis of cohort studies. Metabolism. 2017;75: 36-44.

30. Hamer M, Chida Y. Active commuting and cardiovascular risk: a metaanalytic review. Prev Med. 2008;46(1):9-13.
31. Steell L, Garrido-Méndez A, Petermann F, Díaz-Martínez X, Martínez MA, Leiva AM, et al. Active commuting is associated with a lower risk of obesity, diabetes and metabolic syndrome in Chilean adults. J Public Health. 2017:1-9.

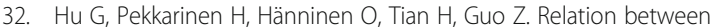
commuting, leisure time physical activity and serum lipids in a Chinese urban population. Ann Hum Biol. 2001;28(4):412-21.

\section{Ready to submit your research? Choose BMC and benefit from:}

- fast, convenient online submission

- thorough peer review by experienced researchers in your field

- rapid publication on acceptance

- support for research data, including large and complex data types

- gold Open Access which fosters wider collaboration and increased citations

- maximum visibility for your research: over $100 \mathrm{M}$ website views per year

At BMC, research is always in progress.

Learn more biomedcentral.com/submissions 